Goldschmidt 2021 Abstract

https://doi.org/10.7185/gold2021.3626

\section{Probing the Ediacaran Shuram excursion by SIMS: Depositional or diagenetic? Global or local?}

\author{
HUAN CUI ${ }^{1,2,3}$, KOUKI KITAJIMA ${ }^{3}$, IAN J. ORLAND ${ }^{3,4}$, \\ SHUHAI XIAO $^{5}$, ALAN J KAUFMAN ${ }^{6}$, JEAN-MARC \\ BAELE $^{7}$, ADAM DENNY $^{3,8}$, MICHAEL J. SPICUZZA ${ }^{3}$, \\ JOHN H. FOURNELLE ${ }^{3}$ AND JOHN W. VALLEY ${ }^{3}$ \\ ${ }^{1}$ Institut de Physique du Globe de Paris (IPGP), Université de \\ Paris \\ ${ }^{2}$ University of Toronto \\ ${ }^{3}$ University of Wisconsin-Madison \\ ${ }^{4}$ Wisconsin Geological and Natural History Survey \\ ${ }^{5}$ Virginia Tech \\ ${ }^{6}$ University of Maryland \\ ${ }^{7}$ University of Mons \\ ${ }^{8}$ Pacific Northwest National Laboratory \\ Presenting Author: huan.cui@ipgp.fr
}

The largest carbon isotope $\left(\delta^{13} \mathrm{C}\right)$ negative anomaly recorded in marine carbonates in Earth history - the Ediacaran Shuram Excursion (SE) - preserves values down to ca. $-10 \%$ on a global scale. Despite the intensive geochemical and theoretical work published in the past decade, its origin and the degree to which its geochemical signature has been diagenetically overprinted is still highly controversial. Notably, SE $\delta^{13} \mathrm{C}$ results that are spatially resolved at the $\mu \mathrm{m}$ scale and strictly based on petrographic context are still limited. To evaluate the potential role and effect of diagenesis in generating the SE, we investigated the SE-equivalent upper Doushantuo Formation at two correlative sections in South China. Multiple generations of carbonate from the intra shelf (lagoonal) Jiulongwan section and the outer shelf (shoal) Zhongling section were analyzed in situ at a $\mu \mathrm{m}$ scale by secondary ion mass spectrometry (SIMS).

Integrated petrographic and SIMS results of the Jiulongwan section do not support the hypothesized occurrence of meteoric and mixing-zone diagenesis or hydrothermal burial diagenesis. Instead, the Jiulongwan limestone shows two generations of carbonate: dominantly calcite microspar $(-9.5$ to $-6.2 \%$, mean $8.2 \%, \mathrm{n}=36)$ with disseminated zoned dolomite crystals $(-11.2$ to $-3.8 \%$, mean $-7.8 \%$, $\mathrm{n}=110)$. The mean values of SIMS $\delta^{13} \mathrm{C}$ in calcite and dolomite of each sample are indistinguishable and consistent with microdrilled bulk-powder $\delta^{13} \mathrm{C}$ values, which we interpret to represent depositional "background" signals; while the variation of SIMS $\delta^{13} \mathrm{C}$ data on a mm scale reflects diagenetic "noise".

The SIMS data of Zhongling also show two generations: positive $\delta^{13} \mathrm{C}$ in dolomite $(+0.2$ to $+4.0 \%$, with a single outlier at $-1.5 \%$, mean $+2.0 \%, \mathrm{n}=25)$ and extremely negative and variable $\delta^{13} \mathrm{C}$ in calcite $(-37.5$ to $-9.3 \%$, mean $-23.2 \%$, $n=54)$. We propose that the SE at Jiulongwan records chemical mixing of oceanic DIC (dissolved inorganic carbon) and methane-derived alkalinity in an anoxic/euxinic water column, whereas the SE interval at Zhongling is characterized by a mixture of dolomicrite derived from the water column and methane-derived authigenic cement formed in pore water. The strong $\delta^{13} \mathrm{C}$ heterogeneity of the SE in South China was therefore modulated by methane oxidation in response to variable local redox conditions. 